\title{
Soil-concrete for use in the 3D printers in the construction of buildings and structures
}

\author{
Petr Iubin $^{1,{ }^{*},}$ and Lubov Zakrevskaya ${ }^{1}$ \\ ${ }^{1}$ Vladimir State University named after Alexander and Nikolay Stoletovs, Institute of architecture, \\ construction and energy, department of construction production, 600000, Gorky 87 Vladimir, Russia
}

\begin{abstract}
Nowadays, the construction of cement composite using 3D printers is considered one of the most promising methods of automation of building processes. However, the compositions of cement composites have several disadvantages, such as high cost, short workability and etc. It has been suggested that clay soil as an additive will help to solve these problems partially. The aim of the work is development the cement compositions with clay soil, for use in 3D printers to construction. The composite consists of cement paste with clay soil and additives. To study printability of a composite the rheological properties in a fresh state were studied. The study of the rheological properties of composites was carried out using a flow table test for mortar. The key factor for determining the suitability of the composite for printing was accepted the diameter of the cone after shaking. The test results showed the possibility of replacing cement paste with clay soil up to $25 \%$ which leads to a reduction in the cost and an increase in printability with a slight decrease in the strength of the obtained material to $7 \%$. Utilizing of soil from the construction site provides maximum economic efficiency of the material application.
\end{abstract}

\section{Introduction}

The purpose of this work is to obtain a composition for 3D printing with the required stiffness, increased print workailability time and low cost. The object of study is cement composites used in $3 \mathrm{D}$ printers.

The task of the study is to investigate existing cement composites for $3 \mathrm{D}$ printers, to develop a number of ground concrete compositions, to study the rheological and mechanical characteristics of the compositions and to identify the most effective. The properties of obtained material must requirements for the compositions used in 3D printers for the construction. The raw materials used in the elaboration of compositions are local deposits of clay soils, portland cement and various additives. Clay soil is a cheap and strong material. It is located in large amounts near construction sites and does not require complex preparation for use as additives or as a main ingredient for soil-concrete building materials.

Nowadays, more often soil-concrete or soil specially reinforced and compacted is used in the foundations of structures, as well as for the construction of roads and airfields.

\footnotetext{
* Corresponding author: petr.lubin@yandex.ru
} 
Usually the soil is strengthened with Portland cement. The compaction of the soil of concrete is very important. A solid monolithic concrete can be obtained, as a result of hardening in moist conditions. It is possible to increase the strength and water resistance of most soils by changing the content of water cement and additives [1-5].

However, soil concrete is not widely used in wall materials, this is due to several reasons. The first one is a high degree of heterogeneity of clay raw materials, even within the one construction site. The second one is determined by physical properties of clay. Soilconcrete with good workability has high shrinkage and low strength when hardened. Fresh soil concrete with high strength and low shrinkage has extremely high stiffness. All these problems can be eliminated by selecting rational water to binder ratio for certain construction objects.

In this study it was supposed that the high stiffness of clay soil can improve the rheological characteristics of cement-based composites for 3D printers [6-11].

Synthesis of new materials is aimed at maximum replacement of cement with clay soil. Currently construction of buildings and structures of cement composite made with 3D printers is considered to be one of the most promising methods for automation of construction processes. Most of the research in this area was focused on development of equipment and technology for 3D printing and materials were paid much less attention. There are still a lot of unsolved problems concerning cement composites in $3 \mathrm{D}$ construction [12-17].

The following requirements are imposed on cement composites for 3D printing.

Extrudability, i. e. a property of a material that characterizes its ability to pass through small holes and nozzles in a fresh state and finally be applied in an even dense layer.

Buildability, a property of a material that characterizes the ability of a layer of this material to retain given shape under its own weight and under the weight of the overlying layers.

Interlaminar connection - the ability to adjacent layers to form a solid cohesive bond, creating a structurally homogeneous printed mass.

Extrudability and hardenability are opposing factors, i. e. high mobility contributes to extrudability, and low mobility contributes to retaining given shape and rapid hardening. An additional point is that an excessively high fluidity of the mixture sometimes causes segregation of the components, and the increased stiffness of the mixture can adversely affect the interlaminar connection. All of the above characteristics are very important and require careful balance to enable high-quality printing [18-25].

Nowadays, there remain many unsolved problems of cement composites for 3D construction. Among them are: high cost, short workability with stable properties, problems related with accelerator as an additive to increase stiffness.

\section{Methods}

A flow table test for cement mortar was used to measure rheological characteristics of cement paste. The equipment applied for measuring slump of cement paste according to GOST310.4-81 is used in different countries for the development of fine cement compositions for $3 \mathrm{D}$ printing.

The method for measuring is as follows:

- Measuring the diameter of the cone base in 4 directions and the height of the cone after slump under the action of gravity.

- Shaking the table by rotating the handle at a frequency of 1 revolution per second, in the amount of 15 times.

- Remeasuring of diameter and height. 
Based on 4 diameter measurements, an average value is calculated. $115 \ldots 125 \mathrm{~mm}$, the diameter value of the cone base after spreading, is the optimum value for $3 \mathrm{D}$ printing. [2628]

This method most accurately defines the set of rheological characteristics of fresh mixture which influence the behaviour of the mixture during application and subsequent resistance to the load from the subsequent layers of the material. The method determines 2 parameters of the material. The parameter characterizing changes in the shape of the mixture cone under its own weight. This parameter can be defined as flowability. The parameter characterizing viscosity, i.e. the rate of the shape change under the influence of the applied external energy. Measurement of compressive and tensile strength was performed after 28 days of hardening, according to GOST 10180-2012.

The table 1 shows characteristics of clay soil used to create composite materials.

Table 1. Characteristics of clay soil.

\begin{tabular}{|c|c|c|c|c|c|c|c|c|c|c|c|}
\hline \multirow{3}{*}{ 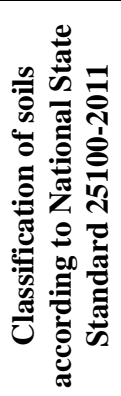 } & \multicolumn{11}{|c|}{ Normative values } \\
\hline & \multicolumn{3}{|c|}{ Moisture, u.s. } & \multirow[b]{2}{*}{ 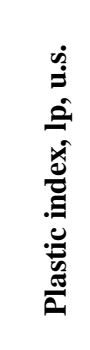 } & \multirow[b]{2}{*}{ 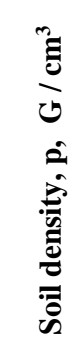 } & \multirow[b]{2}{*}{ 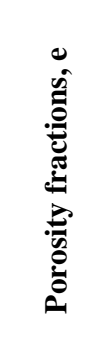 } & \multirow[b]{2}{*}{ 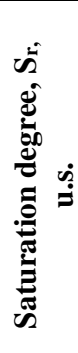 } & \multirow[b]{2}{*}{ 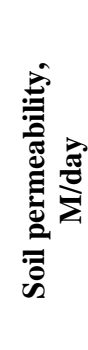 } & \multicolumn{2}{|c|}{$\begin{array}{l}\text { Shearing } \\
\text { strength }\end{array}$} & \multirow[b]{2}{*}{ 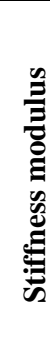 } \\
\hline & $\frac{3}{\frac{i}{\pi}}$ & 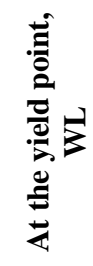 & 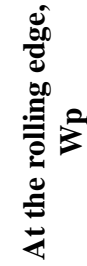 & & & & & & 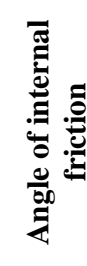 & 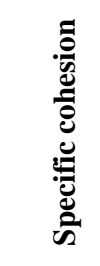 & \\
\hline $\begin{array}{l}\text { Very } \\
\text { soft } \\
\text { loam }\end{array}$ & 0.286 & 0.302 & 0.157 & 0.145 & 1.97 & 0.648 & 1.0 & $<0.1$ & 19 & 0.0119 & 8 \\
\hline
\end{tabular}

Basic composition of the cement paste was chosen from the most commonly used, which additionally requires administration of accelerator 1 minute before the end of mixing, to increase stiffness. Without the accelerator, the spread of the cone is approximately 170 $\mathrm{mm}$. Thus, the introduction of the certain previously unknown amount of clay soil should later lead to spread of the cone to the required values of $115 \ldots 125 \mathrm{~mm}$ [29-32].

Clay content varied from $5 \%$ to $30 \%$ at $5 \%$ intervals. According to the results of previous studies, a soil content of more than $30 \%$ results in the formation of an extremely hard mixture that is not suitable for three-dimensional printing, with the water-cement ratio of less than 0.4. With the water-cement ratio of more than 0.4 the mixture does not satisfy current trends in the production of concrete compositions and GOST 26633-2012.

The synthesized compositions materials are shown in table 2 .

Table 2. The compositions of the synthesized samples.

\begin{tabular}{|c|c|c|c|c|c|c|}
\hline Composition & $\begin{array}{c}\text { Clay } \\
\text { soil, \% }\end{array}$ & $\begin{array}{c}\text { Clay soil, } \\
\text { kg }\end{array}$ & $\begin{array}{c}\text { Cement, } \\
\text { kg }\end{array}$ & $\begin{array}{c}\text { Fly } \\
\text { ash, kg }\end{array}$ & $\begin{array}{c}\text { Water, } \\
\text { kg }\end{array}$ & $\begin{array}{c}\text { Superplasticizer, } \\
\text { kg }\end{array}$ \\
\hline $\begin{array}{c}\text { Control } \\
\text { specimen }\end{array}$ & 0 & 0 & 1.823 & 0.865 & 0.877 & 0.0067 \\
\hline SC3D-1 & 5 & 0.1785 & 1.823 & 0.865 & 0.877 & 0.0067 \\
\hline SC3D-2 & 10 & 0.357 & 1.823 & 0.865 & 0.877 & 0.0067 \\
\hline SC3D-3 & 15 & 0.5355 & 1.823 & 0.865 & 0.877 & 0.0067 \\
\hline SC3D-4 & 20 & 0.714 & 1.823 & 0.865 & 0.877 & 0.0067 \\
\hline SC3D-5 & 25 & 0.8925 & 1.823 & 0.865 & 0.877 & 0.0067 \\
\hline SC3D-6 & 30 & 1.071 & 1.823 & 0.865 & 0.877 & 0.0067 \\
\hline
\end{tabular}


Preparation and proportioning of components.

Mixing composite in 4 stages in a laboratory mortar (cement paste) mixer:

- Adding all ingredients

- Mixing for 2 minutes at a speed of 140 revolutions per minute

- Pausing for 1 minute

- Mixing for 1 minute at a speed of 285 revolutions per minute.

Measurement of rheological characteristics.

Creating Samples.

\section{Results and Discussion}

The results of measuring of the rheological characteristics of fresh soil-concrete using the flow table test are shown in table 3.

Table 3. The results of measuring of the rheological characteristics.

\begin{tabular}{|c|c|c|c|}
\hline Composition & $\begin{array}{c}\text { Diameter after } \\
\text { spreading, mm }\end{array}$ & $\begin{array}{c}\text { Height after } \\
\text { spreading, mm }\end{array}$ & $\begin{array}{c}\text { Conformance to required } \\
\text { diameter 115 .. 125 . mm }\end{array}$ \\
\hline Control specimen & 173 & 30 & No \\
\hline SC3D-1 & 154 & 37 & No \\
\hline SC3D-2 & 141 & 42 & Yes \\
\hline SC3D-3 & 125 & 48 & Yes \\
\hline SC3D-4 & 121 & 53 & Yes \\
\hline SC3D-5 & 115 & 65 & $\begin{array}{c}\text { Too high stiffness, mixing is } \\
\text { difficult, further study of the } \\
\text { sample is not relevant }\end{array}$ \\
\hline SC3D-6 & - & - & \multicolumn{2}{c}{} \\
\hline
\end{tabular}

During the test, an increased stickiness of sample SC3D-4 was noticed. This fact is explained by the fact that clay soil has reached a certain moisture level at which it has maximum stickiness. This state of the composite is very useful for enhancing the cohesion between the layers of material during printing. The formation of a seamless structure is one of the three most important requirements for composite cement material for threedimensional printing.

Figures 1, 2 and 3 show samples of soil concrete in the fresh state while testing on spreading before and after shaking for the control sample, SC3D-2, SC3D-4, respectively.

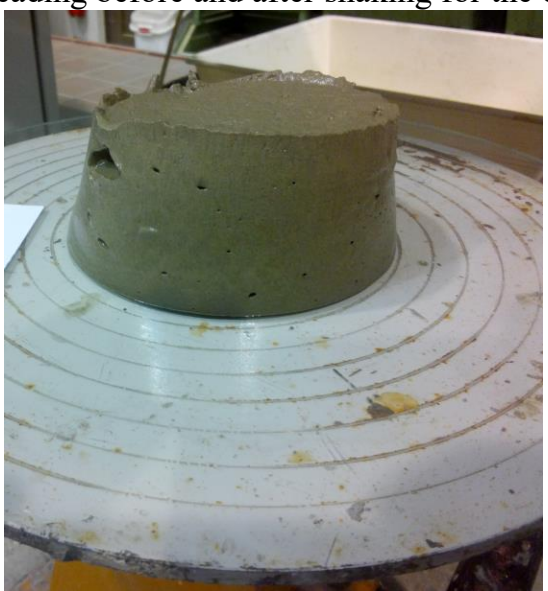

a)

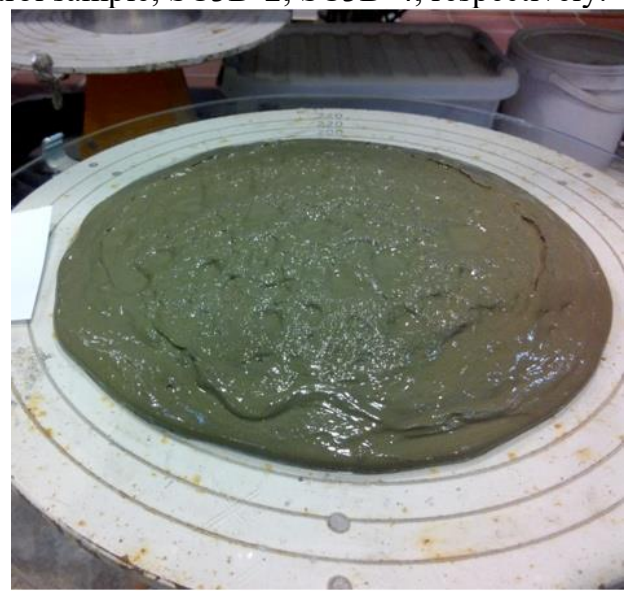

b) 
Fig. 1. Control specimen: a) before shaking; b) after shaking.

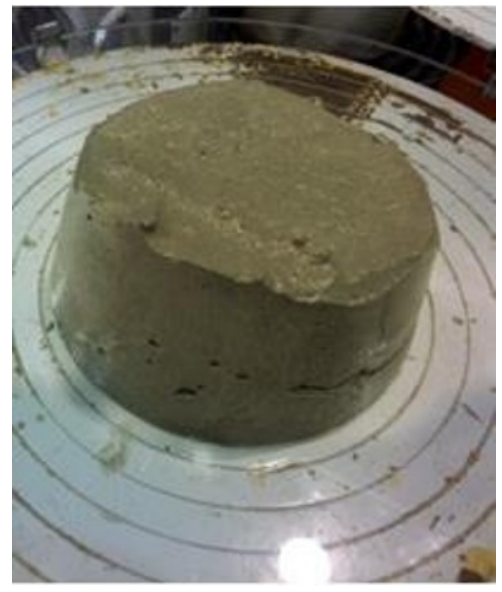

a)

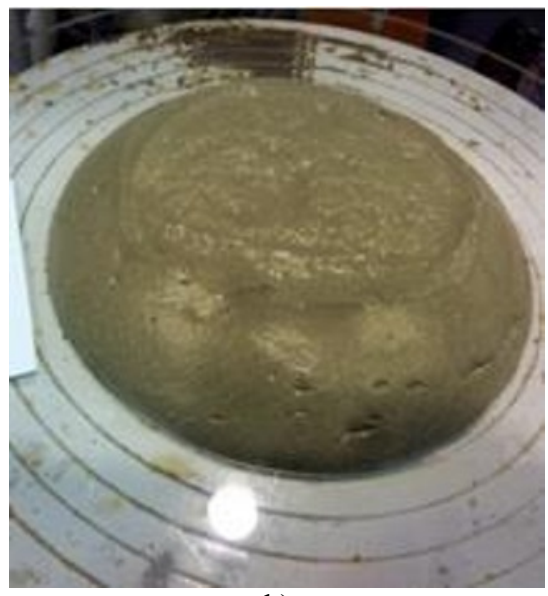

b)

Fig. 2. SC3D-2 : a) before shaking; b) after shaking.

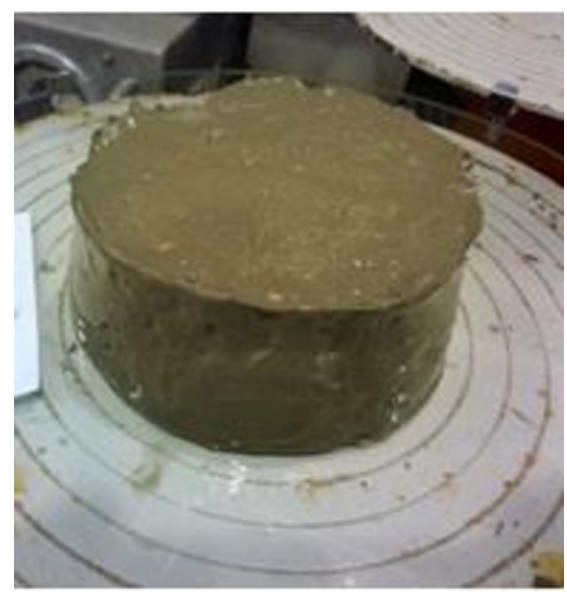

a)

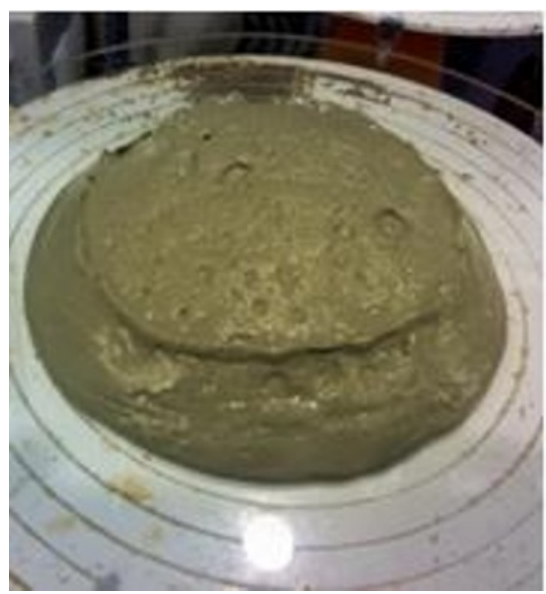

b)

Fig. 3. SC3D-4: a) before shaking; b) after shaking.

Measurement of compressive and tensile strength is shown in table 4.

Table 4. Strength measurement results.

\begin{tabular}{|c|c|c|c|}
\hline Composition & $\begin{array}{c}\text { Tensile } \\
\text { strength, MPa }\end{array}$ & $\begin{array}{c}\text { Compressive } \\
\text { strength, MPa }\end{array}$ & $\begin{array}{c}\text { Compressive strength reduction } \\
\text { compared to control specimen, \% }\end{array}$ \\
\hline $\begin{array}{c}\text { Control } \\
\text { specimen }\end{array}$ & 4.80 & 58.13 & 0 \\
\hline SC3D-1 & 4.85 & 58.05 & $>1$ \\
\hline SC3D-2 & 4.73 & 57.46 & $>1$ \\
\hline SC3D-3 & 4.15 & 57.58 & $>1$ \\
\hline SC3D-4 & 3.97 & 55.93 & 3.8 \\
\hline SC3D-5 & 3.45 & 54.51 & 6.2 \\
\hline
\end{tabular}

Figure 4 shows the samples after the tests of strength. 


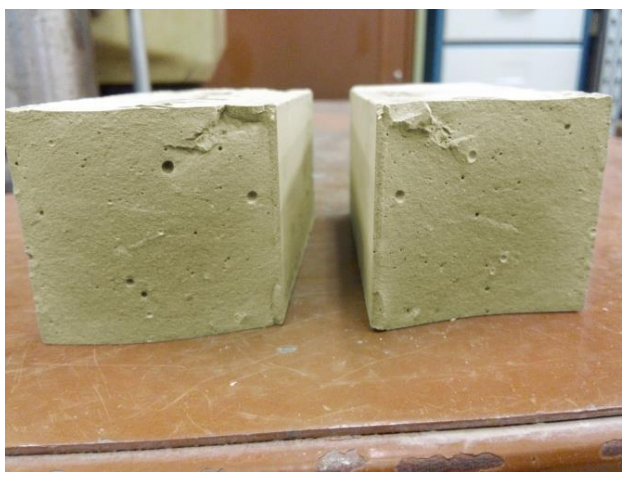

a)

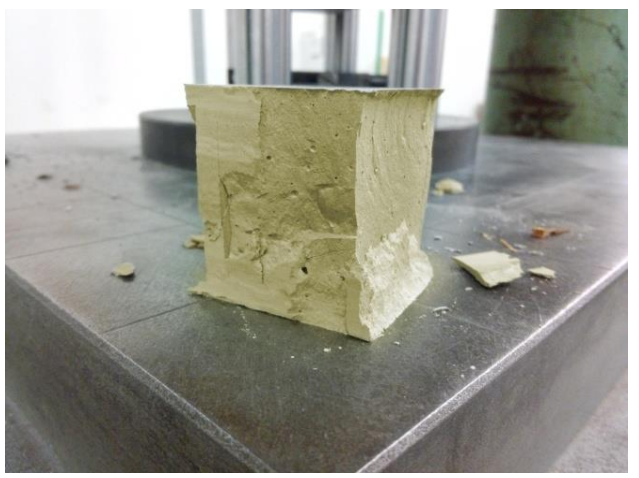

b)

Fig. 4. Samples after the tests of strength: a) after bending test; b) after compression test.

As a result of this study, the positive effect of adding the prepared soil to the cement composite for the three-dimensional additive printing of buildings was revealed. According to the results of the study of rheological properties, the optimum soil content is $20 \%$ for the designed cement composition. According to the results of measurements of strength, a significant decrease in strength in the interval from $15 \%$ to $20 \%$ was noticed. However, reducing the strength by $4 \%$ of a material while replacing $20 \%$ of a material with an almost free material is highly advisable. Consequently, sample SC3D-4 is accepted as an optimum.

Sample SC3D-4 includes $17 \%$ of clay soil, $43 \%$ of cement, $20 \%$ of fly ash, $20 \%$ of water, and $0.00156 \%$ of superplasticizer. Compressive strength is $22 \mathrm{MPa}$, water resistance 0.85 . The task for this chapter is considered to have been achieved; nevertheless, the development of the optimal ratio of components of cement paste for use with a ground additive requires more careful study. First of all, it is an analysis of affect to obtained material of such additives as: fly ash, microsilica, superplasticizer. Also is the study of: water resistance, wear capacity, adhesion, and etc.

\section{Conclusions}

The experimental works proved the possibility of using clay soil as filler for cement paste for 3D printer. The findings suggest that the clay soil influence the properties of composite material in the effective and positive way. The result was achieved by replacing the accelerator in the utilizing composition for 3D printing with clay soil. Experimental studies have established that the introduction of the clay soil to the cement paste in the amount of $5-25 \%$ leads to increase in stiffness by $11-34 \%$ and to decrease in compressive strength by $0.5-6.8 \%$.

Period of workability of fresh printing composition increased more than 2 times, from 60-80 minutes to 160-200 minutes, depending on environmental conditions. Maximum economic efficiency due to application of the material can be achieved by using soil from the construction site. In this case the savings can reach $30 \%$ due to lower transportation costs and costs during construction.

As world experience shows, soil concrete has not previously been used in 3D printers and world experience has no analogues of the formulations developed.

\section{References}

1. M. Polverejan, Y. Liu, T. Pinnavaia, Chemistry of materials, 2283 (2002)

2. M. Smalley, Boca Raton: CRC Press (2006) 
3. I.V. Susoeva, T.N. Vahnina, A.A. Titunin, J.A. Asatkina, Mag. Civ. Eng., 71, 39-50 (2017), doi:10.18720/MCE.71.5

4. S.Y. Shekhovtsova, A.V. Korotkov, M.A. Vysotskaya, Mag. Civ. Eng., 78, 91-100 (2018), doi:10.18720/MCE.78.7

5. T Saarenketo, Journal of Applied Geophysics, 73 (1998)

6. V.Osipov, V. Sokolov, Composition, structure and formation of properties, 576 (2013)

7. R.A. Ibragimov, S.I. Pimenov, V.S. Izotov, Mag. Civ. Eng., 54, 63-69 (2015), doi:10.5862/MCE.54.7

8. A.V. Denisov, Mag. Civ. Eng., 73, 70-87 (2017), doi:10.18720/MCE.73.7

9. R.A. Ibragimov, S.I. Pimenov, Mag. Civ. Eng., 62, 3-12 (2016), doi:10.5862/MCE.62.1

10. A. Polak, I. Fazullin, Colloidn. Journal, 258 (2) (1971)

11. M. Polverejan, Y. Liu, T. Pinnavaia, Chemistry of materials. 2283 (2002)

12. E. Lloret et al. Computer Aided Design. 40 (2015)

13. J. Gardiner, Exploring the Emerging Design Territory of Construction 3D Printing. 42 (2011)

14. A . Tronev, M. Parfenov, P. Agruzov, I. Ilichev, A. Shamrai, Proc. SPIE Int. Soc. Opt. Eng., 10675 (2018)

15. V. Popovich, E. Borisov, A. Popovich, V. Sufiiarov, D. Masaylo, L. Alzina, Mater. Des., 131 (2017)

16. L. Chen et al., Int. J Adv Manuf. Technol., 89 (2017)

17. A.R. Gaifullin, R.Z. Rakhimov, N.R. Rakhimova, Mag. Civ. Eng., 59, 66-73 (2015), doi:10.5862/MCE.59.7

18. J. Galvez, 3D Printing and Additive Manufacturing, 160 (3) (2016)

19. M. Kreiger, B. MacAllister, J. Wilhoit, M. Case, The Proceedings of the 2015 Conference on Autonomous and Robotic Construction of Infrastructure. Ames. Iowa, 149 (2015)

20. F. Bos, R. Wolfs, Z. Ahmed, Virtual Phys. Prototyping, 209 (2016)

21. C. Gosselin, R. Duballet, P. Roux, N. Gaudillière, J. Dirrenberger, Mater. Des., 102 (2016)

22. P. Wu, J. Wang, X. Wang, Autom. Constr., 21 (2016)

23. T.S. Shepelenko, N.P. Gorlenko, O.A. Zubkova, Mag. Civ. Eng., 81, 125-134 (2018), doi:10.18720/MCE.81.13

24. A. Warszawski, R. Navon, Journal of Construction Engineering and Management, 31(1) (1998)

25. G. Tattersall, P. Banfill, Pitman, London. 356 (1983)

26. T. Di Carlo, B. Khoshnevis, A. Carlson, ASME 2013 International Mechanical Engineering Congress and Exposition. American Society of Mechanical Engineer. 62 (2013)

27. T. Le, S. Austin, S. Lim, Mater Struct., 1221 (2012)

28. L.V. Zakrevskaya, P.A. Lubin, S.N. Avdeev, I.A. Gandelsman, S.V. Filippov, Mag. Civ. Eng., 75, 123-128 (2017), doi:10.18720/MCE.75.12

29. S.V. Klyuev, A.V. Klyuev, A.D. Abakarov, E.S. Shorstova, N.G. Gafarova, Mag. Civ. Eng., 75, 66-75 (2017), doi:10.18720/MCE.75.6 
30. D.A. Vakulenko, R.A. Turusov, Mag. Civ. Eng., 75, 106-113 (2017), doi:10.18720/MCE.75.10

31. L.V. Zakrevskaya, A.A. Gavrilenko, S.N. Avdeev, I.A. Gandelsman, A.V. Kireev, Mag. Civ. Eng., 77, 121-129 (2018), doi:10.18720/MCE.77.11

32. M. Gravit, O. Nedryshkin, A. Zhuravlev, , MATEC Web of Conferences, 106 (2017) 